\title{
HUBUNGAN PARITAS DAN PENGGUNAAN KONTRASEPSI HORMONAL DENGAN USIA MENOPAUSE PADA WANITA DI WILAYAH KERJA PUSKESMAS KENTEN PALEMBANG TAHUN 2019
}

\author{
Italia $^{1}$, Eka Trismiyana ${ }^{2}$, Arista Lestari ${ }^{3}$ \\ Program Studi DIII Keperawatan STIKES Mitra Adiguna Palembang \\ Komplek Kenten Permai Blok J No.9-12 Bukit Sangkal Palembang 30114 \\ Email : italia.effendi@gmail.com¹, ekatrismiyana@gmail.com², aristalestari22@gmail.com
}

\begin{abstract}
Abstrak
Menopause merupakan suatu bagian dari proses penuaan pada wanita, termasuk penuaan sistem reproduksi yang menyebabkan seorang wanita tidak lagi mendapat haid.Data dari Puskesmas Kenten Palembang pada tahun 2018 sebanyak 319 orang. Tujuan penelitian ini adalah untuk mengetahui hubungan paritas dan penggunaan kontrasepsi hormonal dengan usia menopause pada wanita di Wilayah Kerja Puskesmas Kenten Palembang tahun 2019. Pada penelitian ini menggunakan metode analitik dengan pendekatan cross sectional. Penelitian ini dilaksanakan pada tanggal 20 Oktober - 04 November 2019. Sampel pada penelitian ini sebanyak 30 orang. Hasil penelitian diketahui distribusi frekuensi responden dengan usia menopause normal sebanyak 19 responden (63,3\%), responden paritas multipara sebanyak 20 responden $(66,7 \%)$, responden yang pernah menggunakan kontrasepsi hormonal sebanyak 25 responden (63,3\%). Hasil analisis bivariat diketahui bahwa ada hubungan antara paritas ( $p$ value $=0,015$ $<\alpha=0,05$ ) dan penggunaan kontrasepsi hormonal ( $p$ value $=0,047<\alpha=0,05$ ) dengan usia menopause di Puskesmas Kenten Palembang. Kesimpulan ada hubungan paritas dan penggunaan kontrasepsi hormonal dengan usia menopause, penelitian ini bertolak belakang dengan teori yang mengatakan makin sering melahirkan maka makin lambat usia menopause dan wanita yang menggunakan kontrasepsi hormonal semakin lambat mengalami usia menopause. Diharapkan tenaga kesehatan agar lebih meningkatkan pelayanan, pemberian informasi melalui konseling atau penyuluhan kepada wanita yang akan mengalami menopause tentang tanda-tanda menopause, dampak baik secara psikilogis maupun fisik sehingga masyarakat menjadi lebih paham tentang menopause.
\end{abstract}

\section{Kata Kunci : Usia Menopause, Paritas, Penggunaan Kontrasepsi Hormonal}

\begin{abstract}
Menopause is a part of the aging process in women, including the aging of the reproductive system, which causes a woman to no longer have menstruation. Data from the Kenten Palembang Health Center in 2018 were 319 people. The purpose of this study was to determine the relationship between parity and the use of hormonal contraceptives with menopausal age in women in the Kenten Palembang Health Center in 2019. This study used an analytical method with a cross sectional approach. This research was conducted on October 20 - November 04 2019. The sample in this study was 30 people. The results showed that the frequency distribution of respondents with normal menopausal age was 19 respondents (63.3\%), multiparity respondents were 20 respondents (66.7\%), respondents who had used hormonal contraception were 25 respondents (63.3\%). The results of the bivariate analysis showed that there was a relationship between parity ( $p$ value $=0.015<\alpha=0.05$ ) and the use of hormonal contraception ( $p$ value $=0.047<\alpha=$ 0.05) and the age of menopause at Puskesmas Kenten Palembang. The conclusion is that there is a relationship between parity and the use of hormonal contraceptives with the age of menopause. This study contradicts the theory which says that the more frequent childbirths, the slower the menopausal age and women who use hormonal contraceptives experience menopause. It is hoped that health workers will further improve services, provide information through counseling or counseling to women who are going through menopause about the signs of menopause, the impact both psychologically and physically so that people become more aware of menopause.
\end{abstract}

Keywords: Age of Menopause, Parity, Use of Hormonal Contraception 


\section{PENDAHULUAN}

Proses seorang individu menjadi tua (menua) merupakan proses menghilangnya secara perlahan-lahan kemampuan jaringan untuk memperbaiki diri/mengganti diri mempertahankan struktur dan fungsi normalnya sehingga tidak dapat bertahan terhadap infeksi dan memperbaiki kerusakan yang diderita. Semua orang yang dikaruniai umur yang panjang, pada suatu saat pasti akan mengalami penuaan. Proses penuaan ini tidak hanya terjadi pada suatu bagian-bagian tertentu saja, tetapi seluruh bagian di tubuh akan mengalami proses penuaan (Lumongga, 2013).

Salah satu indikasi dari keberhasilan pembangunan nasioan dalam bidang kesehatan yaitu apabila meningkatnya angka harapan hidup atau meningkatnya angka kesehatan masyarakat. Menurut laporan WHO pada tahun 2015 usia harapan hidup orang-orang dinegara maju adalah 82 tahun atau lebih, sedangkan orang-orang yang hidup dinegara berkembang diperkirakan angka usia harapan hidupnya 60 tahun (Mulyaningsih dan Paramita, 2018).

Perempuan Indonesia pada umumnya memasuki masa menopause pada usia 46-55 tahun, meskipun begitu tidak menutup kemungkinan bahwa ada beberapa perempuan yang mengalami menstruasi terakhir justru sebelum usia 46 tahun dan ada pula yang mengalami menstruasi terakhir sesudah berusia 57 tahun. Namun apabila diambil rata-ratanya, umumnya seorang perempuan mengalami menopause sekitar usia 46-55 tahun. Pada usia tersebut fungsi endokrin reproduksi mengalami penurunan pada usia 45 tahun dan mulai berhenti pada usia 55 tahun (Mulyaningsih dan Paramita, 2018).

Berdasarkan data dari Profil Kesehatan Indonesia tahun 2017, jumlah wanita usia 45 sampai 49 tahun atau penduduk pra usia lanjut yang memasuki masa menopause sebanyak 8.485.479 orang (Kemenkes RI, 2017).
Selanjutnya di Kota Palembang jumlah wanita berusia 45 sampai 49 tahun yang diperkirakan memasuki menopause tahun 2016 sebanyak 48.002 orang dan tahun 2017 sebanyak 50,545 orang (Dinkes Kota Palembang, 2018).

Menopausesering diartikan sebagai haid terakhir, atau saat terjadinya haid terakhir. Menopause merupakan suatu bagian dari proses penuaan pada wanita, termasuk penuaan sistem reproduksi yang menyebabkan seorang wanita tidak lagi mendapat haid (Lumongga, 2013).

Faktor-faktor yang mempengaruhi usia menopause antara lain kondisi geografis, tingkat perkembangan suatu Negara, dan berbagai karakteristik biologi maupun perilaku populasi. Usia menopause maternal dini, paritas, tingkat social rendah, kebiasaan mengkonsumsi alcohol, merokok serta keadaan gizi yang kurang terpenuhi ataupun akibat dari beberapa penyakit seperti anemia dan tuberculosis, juga berpotensi mengentikan haid (menopause) jauh lebih dini (Mulyaningsih dan Paramita, 2018).

Faktor lain yang berpengaruh terhadap usia menopause adalah faktor jumlah anak. Faktor ini cukup signifikan dengan usia menopause, yaitu semakin sering seorang perempuan melahirkan, maka semakin tua atau lama perempuan tersebut dalam memasuki masa menopause. Hal ini dikarenakan kehamilan dan persalinan akan memperlambat system kerja organ tubuh (Manuaba dalam Mulyaningsih dan Paramita, 2018). Hal ini berbeda dengan faktor pemakaian alat kontrasepsi yang tidak begitu memiliki pengaruh yang signifikan terhadap usia menopause. Namun ada beberapa penelitian yang menemukan korelasi antara lamanya penggunaan kontrasepsi terhadap usia menopause seperti penelitian dari Masruroh yang menunjukkan hasil bahwa ada hubungan riwayat penggunaan kontrasepsi hormonal dengan usia menopause. Perempuan yang menggunakan kontrasepsi yang menekan fungsi indung telur, sehingga tidak dapat 
memproduksi sel telur (Mulyaningsih dan Paramita, 2018)

Data dari Puskesmas Kenten Palembang jumlah wanita yang berusia 45-49 tahun pada tahun 2017 sebanyak 321 orang dan pada tahun 2018 sebanyak 319 orang

Berdasarkan latar belakang di atas peneliti tertarik untuk melakukan penelitian yang berjudul "Hubungan paritas dan penggunaan kontrasepsi hormonal dengan usia menopause pada wanita di Wilayah Kerja Puskesmas Kenten Palembang tahun 2019"

\section{METODE PENELITIAN}

\section{Jenis Penelitian}

Pada penelitian ini menggunakan metode analitik dengan pendekatan cross secitonal.

\section{Waktu dan Tempat Penelitian}

Penelitian ini dilaksanakan di Puskesmas Kenten Palembangpada tanggal 20 0ktober - 04 November 2019.

\section{Subjek Penelitian}

Populasi pada penelitian ini adalah semua wanita menopause yang berada di wilayah kerja Puskesmas Kenten Palembang dengan jumlah sampel sebanyak 30 responden.

\section{Prosedur}

Penelitian ini menggunakan data primer diperoleh dengan cara mengisi kuesioner. Dalam penelitian peneliti menggunakan lembar kuesioner sebagai alat dalam pengumpulan data

\section{Data, Intrumen, dan Teknik Pengumpulan Data}

Dalam penelitian ini menggunakan data primer yang didapat secara langsung dari responden dengan bantuan kuesioner. Dalam penelitian ini data sekunder didapat dari data Profil Puskesmas Kenten Palembang.

\section{Teknik Analisa Data}

Dalam penelitian ini teknik analisa data yang digunakan adalah uji chi square menggunakan analisis univariat dan bivariat untuk mengetahui hubungan paritas dan penggunaan kontrasepsi hormonal dengan usia menopause pada wanita di Wilayah Kerja Puskesmas Kenten Palembang tahun 2019.

\section{HASIL PENELITIAN DAN PEMBAHASAN}

\section{Analisis Univariat}

Analisis ini dilakukan untuk mengetahui distribusi frekuensi dan presentase dari variabel usia menopause, paritas dan penggunaan kontrasepsi hormonal.

\section{Karaksteristik Responden Berdasarkan Umur}

Tabel 4.1

Distribusi Frekuensi Karakteristik Umur Responden di Puskesmas Kenten Palembang Tahun 2019

\begin{tabular}{cccc}
\hline No & Umur & Frekuensi & Presentase \\
\hline 1 & $46-55$ & 9 & 30 \\
2 & $56-65$ & 21 & 70 \\
\hline \multicolumn{2}{l}{ Total } & 30 & 100 \\
\hline
\end{tabular}

Berdasarkan tabel 4.1 diatas dari 30 responden yang paling banyak pada umur 56 - 65 tahun yang berjumlah 21 responden $(70 \%)$.

\section{Paritas}

Tabel 4.2

Distribusi Frekuensi Paritas Responden di Puskesmas Kenten Palembang Tahun 2019

\begin{tabular}{cccc}
\hline No & Paritas & Frekuensi & Presentase \\
\hline 1 & Primipara & 0 & 0 \\
2 & Multipara & 20 & 66,7 \\
\hline 3 & Grandemultipara & 10 & 33,3 \\
\hline & Total & 30 & 100 \\
\hline
\end{tabular}

Berdasarkan tabel 4.2 diatas menunjukkan dari 30 responden paritas multipara sebanyak 20 responden $(66,7 \%)$ 
dan responden paritas grandemultipara sebanyak 10 responden $(33,3 \%)$.

\section{Penggunaan Kontrasepsi Hormonal}

Tabel 4.3

Distribusi Frekuensi Penggunaan Kontrasepsi Hormonaldi Puskesmas Kenten Palembang Tahun 2019

\begin{tabular}{cccc}
\hline No & $\begin{array}{c}\text { Penggunaan } \\
\text { Kontrasepsi } \\
\text { Hormonal }\end{array}$ & Frekuensi & Presentase \\
\hline 1 & Pernah & 25 & 63,3 \\
2 & Tidak pernah & 5 & 16,7 \\
\hline & Total & 30 & 100 \\
\hline
\end{tabular}

Berdasarkan tabel 4.3 diatas menunjukkan dari 30 responden yang pernah menggunakan kontrasepsi hormonal sebanyak 25 responden $(63,3 \%)$ dan responden yang tidak pernah menggunakan kontrasepsi hormonal sebanyak 5 responden $(16,7 \%)$.

\section{Usia Menopause}

Tabel 4.4

Distribusi Frekuensi Usia Menopause di Puskesmas Kenten Palembang

Tahun 2019

\begin{tabular}{cccc}
\hline No & Usia Menopause & Frekuensi & Presentase \\
\hline 1 & Cepat & 0 & 0 \\
2 & Normal & 19 & 63,3 \\
\hline 3 & Lambat & 11 & 36,7 \\
\hline & Total & 30 & 100 \\
\hline
\end{tabular}

Berdasarkan tabel 4.2 diatas dari 30 responden dengan usia menopause normal sebanyak 19 responden $(63,3 \%)$ dan usia menopause lambat sebanyak 11 responden $(36,7 \%)$.

\section{Analisis Bivariat}

\section{Hubungan Antara Paritas dengan Usia Menopause}

Tabel 4.5

Hubungan Antara Paritas dengan Usia Menopausedi Puskesmas Kenten Palembang

\begin{tabular}{|c|c|c|c|c|c|c|c|c|}
\hline \multirow{3}{*}{ Paritas } & \multicolumn{4}{|c|}{ Usia Menopause } & \multirow{2}{*}{\multicolumn{2}{|c|}{ Jumlah }} & \multirow{3}{*}{$\begin{array}{c}p \\
\text { value }\end{array}$} & \multirow{3}{*}{$O R$} \\
\hline & \multicolumn{2}{|c|}{ Normal } & \multicolumn{2}{|c|}{ Lambat } & & & & \\
\hline & $\mathbf{n}$ & $\%$ & $\mathbf{n}$ & $\%$ & $\mathbf{N}$ & $\%$ & & \\
\hline Multipara & 16 & 80 & 4 & 20 & 20 & 100 & \multirow{2}{*}{0,015} & \multirow{2}{*}{9,33} \\
\hline Grandemultipara & 3 & 30 & 7 & 70 & 10 & 100 & & \\
\hline 11 & & 30 & 100 & & & & & \\
\hline
\end{tabular}

Berdasarkan tabel 4.5 di atas diketahui bahwa dari 20 responden paritas multipara yang mengalami usia menopause normal (45 - 55 tahun) sebanyak 16 responden (80\%) sedangkan dari 10 responden paritas grandemultipara (melahirkan $\geq 5$ kali) yang mengalami usia menopause normal sebanyak 3 responden $(30 \%)$.

Dari hasil uji statistik chi square didapatkan nilai $p$ value $=0,015<\alpha=(0,05)$ yang berarti bahwa ada hubungan antara paritas dengan usia menopause di Puskesmas Kenten Palembang. Hasil Odds Ratio didapatkan nilai 9,33 yang berarti bahwa responden paritas grandmultipara berpeluang 9,33 kali lebih besar mengalami usia menopause normal dibandingkan dengan paritas multipara.

\section{Hubungan Antara Penggunaan Kontrasepsi Hormonal dengan Usia Menopause}

Tabel 4.6

Hubungan Antara Penggunaan Kontrasepsi Hormonal dengan Usia Menopause di Puskesmas Kenten Palembang Tahun 2019

\begin{tabular}{|c|c|c|c|c|c|c|c|c|}
\hline \multirow{3}{*}{$\begin{array}{l}\text { Penggunaan } \\
\text { kontrasepsi } \\
\text { hormonal }\end{array}$} & \multicolumn{4}{|c|}{ Usia Menopause } & \multirow{2}{*}{\multicolumn{2}{|c|}{ Jumlah }} & \multirow{3}{*}{$\underset{\text { value }}{p}$} & \multirow{3}{*}{ OR } \\
\hline & \multicolumn{2}{|c|}{ Normal } & \multicolumn{2}{|c|}{ Lambat } & & & & \\
\hline & $\mathbf{n}$ & $\%$ & $\mathbf{n}$ & $\%$ & $\mathbf{N}$ & $\%$ & & \\
\hline Pernah & 18 & 72 & 7 & 28 & 25 & 100 & 0,04 & \multirow{2}{*}{10,286} \\
\hline Tidak pernah & 1 & 20 & 4 & 80 & 5 & 100 & 7 & \\
\hline 19 & 11 & & & & & & & \\
\hline
\end{tabular}

Berdasarkan tabel 4.6 di atas diketahui bahwa dari 25 responden yang pernah menggunakan kontrasepsi hormonal yang mengalami usia menopause normal sebanyak 18 responden (72\%) sedangkan dari 5 responden yang tidak pernah menggunakan kontrasepsi hormonal yang 
mengalami usia menopause normal sebanyak 1 responden $(20 \%)$.

Dari hasil uji statistik chi square didapatkan nilai $p$ value $=0,047<\alpha=(0,05)$ yang berarti bahwa ada hubungan antara penggunaan kontrasepsi hormonal dengan usia menopause di Puskesmas Kenten Palembang. Hasil Odds Ratio didapatkan nilai 10,286 yang berarti bahwa responden yang menggunakan kontrasepsi hormonal berpeluang 10,286 kali lebih besar mengalami usia menopause normal dibandingkan dengan yang tidak menggunakan kontrasepsi hormonal.

\section{Pembahasan}

\section{Analisis Univariat}

\section{Usia Menopause}

Berdasarkan hasil penelitian diketahui bahwa dari 30 responden dengan usia menopause normal sebanyak 19 responden $(63,3 \%)$ dan usia menopause lambat sebanyak 11 responden $(36,7 \%)$.

Hasil penelitian ini sesuai dengan pendapat Ratnawati (2018), menopause berasal dari kata yunani men (bulan) dan pausis (berhenti) merupakan matinya sebuah siklus menstruasi karena hormon yang diproduksi dalam sistem reproduksi tepatnya di ovarium mengalami penurunan hingga tidak lagi beroperasi. Akibatnya penderita tidak lagi memproduksi sel telur pada ovariumnya dan wanita ini tidak lagi bisa hamil. Bahkan selera hubungan seksual pun menurun.

Penelitian ini sejalan dengan hasil penelitian Purnama (2016) tentang gambaran usia menopause pada wanita di Wilayah Kerja Puskesmas Kota Kendari Sulawesi Tenggara. Hasil penelitian menunjukkan sebagian besar usia menopause dalam kategori normal (usia 45-55 tahun). Sebagian besar usia menopause dalam kategori normal dan lambat memiliki paritas multipara. Sebagian besar usia menopause dalam kategori normal dan lambat memiliki riwayat penggunaan kontrasepsi hormonal.

Dari uraian di atas peneliti berpendapat bahwa mayoritas responden mengalami menopause pada usia normal yaitu 46 - 55 tahun. Menurut Teori Kumalasari (2012), usia menopause dapat dipengaruhi oleh berbagai faktor antara lain paritas, penggunaan kontrasepsi hormonal, usia haid pertama, usia melahirkan, faktor psikis, wanita dengan histerektomi, merokok, sosial wkonomi, budaya dan lingkungan.

\section{Hubungan Paritas dengan Usia Menopause}

Berdasarkan hasil penelitian diketahui bahwa dari 30 responden paritas multipara sebanyak 20 responden $(66,7 \%)$ dan responden paritas grandemultipara sebanyak 10 responden $(33,3 \%)$.

Hasil analisis bivariat diketahui bahwa dari 20 responden paritas multipara yang mengalami usia menopause normal sebanyak 16 responden (80\%) sedangkan dari 10 responden paritas grandemultipara yang mengalami usia menopause normal sebanyak 3 responden (30\%). Dari hasil uji statistik chi square didapatkan nilai $p$ value $=0,015<\alpha=(0,05)$ yang berarti bahwa ada hubungan antara paritas dengan usia menopause di Puskesmas Kenten Palembang. Hasil Odds Ratio didapatkan nilai 9,33 yang berarti bahwa responden paritas grandmultipara berpeluang 9,33 kali lebih besar mengalami usia menopause normal dibandingkan dengan paritas multipara.

Pada penelitian hubungan paritas dan penggunaan kontrasepsi hormoan dengan usia menopause di Wilayah kerja Puskesmas Kenten Palembang tahun 2019 yaitu responden yang melahirkan multipara mayoritas mengalami usia menopause normal, hal ini bertolak belakang dengan teori Kumalasari (2012), beberapa peneliti menemukan bahwa makin sering wanita melahirkan 
maka semakin tua atau lama mereka memasuki masa menopause.

Penelitian ini juga sejalan dengan teori Nurdianti (2018), ibu yang belum pernah melahirkan cenderung lebih cepat mengalamimenopause, hal ini disebabkan karena wanitamenstruasi yang tidak disertai dengan prosespembuahan atau tidak terjadi proses fertilisasi akanmenyebabkan jumlah folikel dalam ovarium yangmengalami degradasi atau mengalami penurunanjumlah folikel (struktur berisi cairan yang merupakan tempat pertumbuhan sel-telur), hal inilah yang dapat menyebabkan terjadinya menopause dini atau lebih muda. Semakin sering seorang wanita melahirkan maka semakin tua atau lama mereka memasuki menopause.

Penelitian ini juga sejalan dengan pendapat Mulyaningsih dan Paramita (2018), faktor lain yang berpengaruh terhadap usia menopause adalah faktor jumlah anak. Faktor ini cukup signifikan dengan usia menopause, yaitu semakin sering seorang perempuan melahirkan, maka semakin tua atau lama perempuan tersebut dalam memasuki masa menopause. Hal ini dikarenakan kehamilan dan persalinan akan memperlambat system kerja organ tubuh.

Hasil penelitian ini juga sejalan dengan penelitian Purnama (2016) tentang gambaran usia menopause pada wanita di Wilayah Kerja Puskesmas Kota Kendari Sulawesi Tenggara. Hasil penelitian menunjukkan sebagian besar usia menopause dalam kategori normal (usia 45-55 tahun). Sebagian besar usia menopause dalam kategori normal dan lambat memiliki paritas multipara.

Dari uraian di atas peneliti berasumsi bahwa berdasarkan teori Kumalasari (2012) semakin sering seorang wanita melahirkan maka semakin tua atau lama perempuan tersebut dalam memasuki masa menopause karena kehamilan dan persalinan akan memperlambat sistem kerja organ tubuh. Begitu juga sebaliknya wanita yang belum pernah hamil atau kehamilan sedikit akanmenyebabkan jumlah folikel dalam ovarium yangmengalami degradasi atau mengalami penurunanjumlah folikel (struktur berisi cairan yang merupakan tempat pertumbuhan sel-telur), hal inilah yang dapat menyebabkan terjadinya menopause dini atau lebih muda.

3. Hubungan Penggunaan Kontrasepsi Hormonal dengan Usia Menopause

Berdasarkan hasil penelitian diketahui bahwa dari 30 responden yang pernah menggunakan kontrasepsi hormonal sebanyak 25 responden $(63,3 \%)$ dan responden yang tidak pernah menggunakan kontrasepsi hormonal sebanyak 5 responden (16,7\%).

Hasil analisis bivariat diketahui bahwa dari 25 responden yang pernah menggunakan kontrasepsi hormonal yang mengalami usia menopause normal sebanyak 18 responden (72\%) sedangkan dari 5 responden yang tidak pernah menggunakan kontrasepsi hormonal yang mengalami usia menopause normal sebanyak 1 responden (20\%). Dari hasil uji statistik chi square didapatkan nilai $p$ value $=0,047<\alpha=(0,05)$ yang berarti bahwa ada hubungan antara penggunaan kontrasepsi hormonal dengan usia menopause di Puskesmas Kenten Palembang. Hasil Odds Ratio didapatkan nilai 10,286 yang berarti bahwa responden yang menggunakan kontrasepsi hormonal berpeluang 10,286 kali lebih besar mengalami usia menopause normal dibandingkan dengan yang tidak menggunakan kontrasepsi hormonal.

Hasil penelitian ini sesuai dengan Fibrila (2014), pada ibu yang memiliki riwayat pemakaian kontrasepsi hormonal, kandungan hormon estrogen dan progesteron yang ada pada kontrasepsi hormonal berdampak pada perubahan hormonal pada ovarium, 
karena tubuh terus menerus diberikan maka merangsang hipofisis tidak memproduksi kedua hormon tersebut sehingga hormon estrogen dan progesteron tidak diproduksi. Perubahan hormon tersebut menyebabkan perubahan haid, ada yang tidak teratur bahkan ada yang mundur, seperti diketahui menstruasi terjadi karena adanya hormon estrogen dan progesterone yang secara stimulan merangsang pembentukan endometrium. Pembentukan hormon - hormon tersebut dilakukan oleh kedua indung telur. Perangsangan dari terbentuknya hormon tersebut karena adanya FSH (folikel stimulating hormone) dan LH (luteinizing hormone).

Hasil penelitian ini sesuai dengan teori Manuaba (2010), kontrasepsi hormonal merupakan kontrasepsi dimana estrogen dan progesteron memberikan umpan balik terhadap kelenjar hipofisis melaluihipotalamus sehingga terjadi hambatan terhadap folikel dan proses ovulasi.

Penelitian ini juga sejalan dengan pendapat Mulyaningsih dan Paramita (2018), ada beberapa penelitian yang menemukan korelasi antara lamanya penggunaan kontrasepsi terhadap usia menopause seperti penelitian dari Masruroh yang menunjukkan hasil bahwa ada hubungan riwayat penggunaan kontrasepsi hormonal dengan usia menopause. Perempuan yang menggunakan kontrasepsi yang menekan fungsi indung telur, sehingga tidak dapat memproduksi sel telur.

Hasil penelitian ini juga sejalan dengan penelitian Purnama (2016) tentang gambaran usia menopause pada wanita di Wilayah Kerja Puskesmas Kota Kendari Sulawesi Tenggara. Hasil penelitian menunjukkan sebagian besar usia menopause dalam kategori normal (usia 45-55 tahun). Sebagian besar usia menopause dalam kategori normal dan lambat memiliki riwayat penggunaan kontrasepsi hormonal.

Dari uraian di atas peneliti berasumsi bahwa berdasarkan teori Prawirohardjo (2014) pada wanita yang menggunakan kontrasepsi ini akan lebih lama atau tua memasuki menopause. Penggunaan kontrasepsi hormonal mempengaruhi usia menopause, wanita yang menggunakan kontrasepsi hormonal dalam jangka waktu yang relatif lama akan mengalami menopause lebih cepat karena cara kerja kontrasepsi hormonal yang menekan fungsi indung telur, sehingga tidak dapat memproduksi sel telur. Pada penelitian ini hasil yang didapatkan bertolak belakang yaitu responden yang pernah menggunakan kontrasepsi hormonal mayoritas mengalami usia menopause normal.

\section{KESIMPULAN}

Dari hasil penelitian yang telah diuraikan sebelumnya, maka dapat ditarik kesimpulan sebagai berikut :

1. Distribusi frekuensi responden dengan usia menopause normal sebanyak 19 responden $(63,3 \%)$ dan usia menopause lambat sebanyak 11 responden $(36,7 \%)$, kesimpulan mayoritas responden usia menopause normal.

2. Distribusi frekuensi responden paritas multipara sebanyak 20 responden $(66,7 \%)$ dan responden paritas grandemultipara sebanyak 10 responden (33,3\%), mayoritas responden paritas multipara.

3. Distribusi frekuensi responden yang pernah menggunakan kontrasepsi hormonal sebanyak 25 responden $(63,3 \%)$ dan responden yang tidak pernah menggunakan kontrasepsi hormonal sebanyak 5 responden $(16,7 \%)$, mayoritas responden pernah menggunakan kontrasepsi homornal.

4. Ada hubungan antara paritas dengan usia menopause di Puskesmas Kenten $\operatorname{Palembang}(p$ value $=0,015<\alpha=0,05)$ 
5. Ada hubungan antara penggunaan kontrasepsi hormonal dengan usia menopause di Puskesmas Kenten Palembang $(p$ value $=0,047<\alpha=0,05)$

\section{SARAN}

\section{Bagi Puskesmas Kenten Palembang}

Diharapkan tenaga kesehatan agar lebih meningkatkan pelayanan, pemberian informasi melalui konseling atau penyuluhan kepada wanita yang akan mengalami menopause tentang tanda-tanda menopause, dampak baik secara psikilogis maupun fisik sehingga masyarakat menjadi lebih paham tentang menopause.

\section{Bagi Institusi Pendidikan}

Hasil penelitian ini dapat dijadikan sebagai bahan referensi dan menambah kepustakaan di STIKES Mitra Adiguna Palembang dalam melakukan penelitian khususnya yang berhubungan usia menopause.

\section{Bagi Peneliti Selanjutnya}

Diharapkan agar dapat meneliti variabel lain yang lebih bervariasi seperti faktor genetik, usia terakhir melahirkan. Sehingga penelitian tentang usia menopause hasilnya dapat lebih baik lagi.

\section{DAFTAR PUSTAKA}

Fibrila Firda. 2014. Hubungan usia melahirkan terakhir, riwayat pemakaian kontrasepsi,menarche dan budaya dengan menopause di kelurahan Mulyosari Kecamatan Metro Barat. Jurnal Poltekkes Kemenkes Tanjungkarang.

Friedman, M. 2010. Buku Ajar Keperawatan keluarga : Riset, Teori, dan Praktek.. Jakarta: EGC.

Haryono Rudi. 2016. Siap menghadapi Menstruasi dan Menopause. Yogyakarta. Goysen Publishing.
Kumalasari, Intan. 2012. Kesehatan Reproduksi Untuk Mahasiswa Kebidanan dan Keperawatan. Jakarta : Salemba Medika.

Lumongga, Lubis Namora. 2013. Buku PSIKOLOGI KESPRO Wanita dan Perkembangan Reproduksinya. Cetakan ke-1. Jakarta : Prananda Media Group.

Manuaba, Ida Bagus Gede.2010. Ilmu Kebidanan, Penyakit Kandungan dan Keluarga Berencana untuk Pendidikan Bidan. Jakarta : EGC,

Mulyaningsih Sundari dan Paramita Pradnya Dyah. 2018. Klimakterium Masalah dan Penanganannya dalam Perspektif Kebidanan. Yogyakarta. Pustaka baru

Notoatmodjo, S. 2012. Metodelogi Penelitian Kesehatan. Jakarta : Rineka Cipta.

Nurdianti Ninyng. 2018. Hubungan paritas dengan usia menopause di Padukuhan Cangkringan. Jurnal Univ. Respati Yogyakarta.

Potter \& Perry. 2010. Buku Ajar Fundamental Keperawatan. Jakarta: EGC.

Prawirohardjo, Sarwono. 2014. Ilmu Kebidanan. Jakarta: YBPSP.

Profil Puskesmas Kenten Palembang tahun 2019.

Purnama. 2016. Gamabran Usia Menopause pada Wanita di Wilayah Kerja Puskesmas Kota Kendari Sulawesi Tenggara. Jurnal

Purwoastuti Endang. 2008. Menopause, Siapa Takut?. Yogyakarta. Kanisius

Ratnawati, Ana. 2018. Buku Asuhan Keperawatan Pada Pasien Dengan Gangguan Sistem Reproduksi. Yogyakarta : Pustaka Baru Press. 
Saifuddin, Abdul Bari, dkk. 2010. Buku Panduan Praktis Pelayanan Kontrasepsi. Jakarta: Yayasan Bina Pustaka Sarwono Prawirohardjo.

Sulistyawati, A. 2014. Pelayanan Keluarga Berencana. Jakarta: Salemba Medika 